\title{
Comparison of carotid atherosclerotic plaques between subjects in Northern and Southern China: a Chinese atherosclerosis risk evaluation study
}

\author{
Dandan Yang (D , ${ }^{1}$ Yang $\mathrm{Ji}^{2}{ }^{2}$ Dan Wang, ${ }^{2}$ Hiroko Watase, ${ }^{3}$ Daniel S Hippe, ${ }^{4}$ \\ Xihai Zhao, ${ }^{5}$ Chun Yuan ${ }^{4}$
}

To cite: Yang D, Ji Y, Wang D, et al. Comparison of carotid atherosclerotic plaques between subjects in Northern and Southern China: a Chinese atherosclerosis risk evaluation study. Stroke \& Vascular Neurology 2020;5: e000288. doi:10.1136/svn-2019-000288

- Additional material is published online only. To view please visit the journal online (http://dx.doi.org/10.1136/svn2019-000288).

DY and YJ contributed equally.

DY and YJ are joint first authors.

Received 10 October 2019 Revised 5 December 2019 Accepted 30 December 2019 Published Online First 29 January 2020

Check for updates

(C) Author(s) (or their employer(s)) 2020. Re-use permitted under CC BY-NC. No commercial re-use. See rights and permissions. Published by BMJ.

For numbered affiliations see end of article.

Correspondence to

Dr. Xihai Zhao;

xihaizhao@tsinghua.edu.cn

\section{ABSTRACT}

Background and purpose To investigate differences in the characteristics of carotid atherosclerotic plaques of symptomatic subjects in northern and southern China using MRI.

Methods Sixty-three subjects in northern China (mean age: $59.1 \pm 8.6$ years, 45 men) and 56 subjects in southern China (mean age: $60.4 \pm 8.6$ years, 38 men) were included. All subjects underwent carotid artery multicontrast vessel wall MRI. Plaque morphology, calcification, lipidrich necrotic core, intraplaque haemorrhage, luminal surface disruption and high-risk plaque were measured and identified. All plaque characteristics were compared between subjects in northern and southern China using Mann-Whitney U test or $\chi^{2}$ test.

Results Compared with subjects in southern China, those in northern China had significantly greater areas for lumen $\left(57.7 \pm 14.9 \mathrm{~mm}^{2}\right.$ vs $\left.50.4 \pm 18.3 \mathrm{~mm}^{2}, p=0.009\right)$, wall $\left(38.4 \pm 13.1 \mathrm{~mm}^{2}\right.$ vs $\left.31.9 \pm 11.7 \mathrm{~mm}^{2}, p<0.001\right)$ and total vessel $\left(96.1 \pm 20.2 \mathrm{~mm}^{2}\right.$ vs $\left.82.4 \pm 22.7 \mathrm{~mm}^{2}, \mathrm{p}=0.001\right)$ and mean wall thickness $(1.25 \pm 0.43 \mathrm{~mm}$ vs $1.13 \pm 0.40 \mathrm{~mm}$, $\mathrm{p}=0.019) \cdot \chi^{2}$ analysis showed that subjects in northern China tended to have a higher prevalence of intraplaque haemorrhage $(14.3 \%$ vs $5.4 \%, p=0.106)$ and high-risk plaque $(20.6 \%$ vs $10.7 \%, p=0.140)$ than those in southern China, although these differences were not statistically significant (all $\mathrm{p}>0.05$ ).

Conclusion Subjects in northern China have significantly larger vessel size and may have a higher prevalence of vulnerable plaques than those in southern China. Our findings provide additional perspective to optimise the management of cerebrovascular disease in individuals in different regions in China.

Trial registration number NCT02017756

\section{INTRODUCTION}

Globally, stroke is the second leading cause of death and the third most common cause of disability. ${ }^{12}$ In China, stroke has become the leading cause of death and disability. ${ }^{3}$ Geographical variations in stroke incidence, mortality and prevalence have been reported in China. ${ }^{3}{ }^{4}$ Wang et at demonstrated that the incidence of stroke in northern China is significantly higher than that in southern China $\left(275.3 / 10^{5}\right.$ vs $154.6 / 10^{5}$, $\left.\mathrm{p}<0.002\right)$. It is well evidenced that carotid vulnerable atherosclerotic plaques, defined as lesions with intraplaque haemorrhage (IPH), large lipidrich necrotic core (LRNC) or luminal surface disruption, including ulcer and fibrous cap rupture, ${ }^{5}$ are associated with ischaemic stroke. $\mathrm{Pu}$ et $a t^{6}$ reported that subjects in northern China were more likely to have carotid atherosclerotic stenosis than those in southern China. However, the differences in lumen area, wall area and thickness, and plaque components in the carotid artery have not been fully investigated between northern and southern symptomatic Chinese patients.

Multicontrast vessel wall MRI has been established to be capable of accurately assessing the morphology and compositional features of carotid atherosclerotic plaque. Luo $e t a l^{7}$ reported that multicontrast vessel wall MRI was well validated by histology in measuring the carotid atherosclerotic plaque burden and luminal stenosis. In addition, previous studies have indicated that carotid plaque components such as LRNC, calcification, IPH and luminal surface disruption can be accurately estimated by multicontrast vessel wall MRI. ${ }^{8}$

Above all, this study aimed to investigate the differences in the morphological and compositional features of carotid atherosclerotic plaques in symptomatic subjects in northern and southern China using multicontrast vessel wall MRI.

\section{METHODS}

\section{Study population}

All subjects were enrolled from CARE-II (Chinese Atherosclerosis Risk Evaluation), a cross-sectional, multicentre study. The aim of the CARE-II study was to assess the prevalence and characteristics of carotid high-risk atherosclerotic plaques in Chinese subjects with recent ischaemic stroke or transient ischaemia 
attack using multicontrast MRI. The study protocol of CARE-II study has been reported previously. ${ }^{9}$ In brief, the CARE-II study enrolled subjects aged 18-80 years old who suffered from a recent stroke or transient ischaemia attack and had atherosclerotic plaques in at least one carotid artery determined by B-mode ultrasound imaging. All subjects underwent carotid artery multicontrast vessel wall MRI. Geographically, China is divided into northern and southern regions according to the boundary of Yangtze River. Of the locations of 14 hospitals in the CARE-II study, two provinces, Heilongjiang and Guangdong, were selected to be representative of northern and southern China, respectively. In the present study, we finally included subjects recruited at Harbin Medical University Fourth Hospital and Qiqihar First Hospital in the province of Heilongjiang and subjects recruited at Zhujiang Hospital and Sun Yat-sen Memorial Hospital in the province of Guangdong. The clinical characteristics of all subjects, such as age, sex, height, weight, body mass index (BMI), history of smoking, hypertension, hyperlipidaemia, diabetes, coronary heart disease, statin use, antihypertension medication use, blood pressure and lipid levels, were collected from their medical records.

\section{Carotid artery MRI}

Multicontrast vessel wall MRI of the carotid arteries was performed for all included subjects on 3.0T MRI scanners (Achieva TX, Philips Healthcare, The Netherlands) with dedicated eight-channel carotid coils. In the multicontrast MRI protocol, time-of-flight (TOF), T1-weighted (T1W), T2-weighted (T2W) and magnetisation-prepared rapid acquisition gradient echo (MPRAGE) sequences were acquired using the following parameters: TOF: repeat time (TR)/echo time (TE) $20 \mathrm{~ms} / 4.9 \mathrm{~ms}$, field of view (FOV) $14 \times 14 \mathrm{~cm}^{2}$, flip angle $20^{\circ}$, matrix $256 \times 256$, and slice thickness $1 \mathrm{~mm}$; T1W quadruple inversion recovery: TR/TE $800 \mathrm{~ms} / 10 \mathrm{~ms}$, FOV $14 \times 14 \mathrm{~cm}^{2}$, matrix $256 \times 256$, and slice thickness $2 \mathrm{~mm}$; T2W multislice double inversion recovery: TR/TE $4800 \mathrm{~ms} / 50 \mathrm{~ms}$, FOV $14 \times 14 \mathrm{~cm}^{2}$, matrix 256 $\times 256$, and slice thickness $2 \mathrm{~mm}$; and MPRAGE: TR/TE $8.8 \mathrm{~ms} / 5.3 \mathrm{~ms}$, FOV $14 \times 14 \mathrm{~cm}^{2}$, flip angle $15^{\circ}$, matrix $256 \times 256$, and slice thickness $1 \mathrm{~mm}$. All imaging was centred to the symptomatic side of carotid artery bifurcation with longitudinal coverage of $32 \mathrm{~mm}$.

\section{MRI analysis}

Two trained reviewers with more than 3 years' experience in plaque imaging interpreted the carotid MRI using custom-designed software (CASCADE; University of Washington, Seattle, USA) ${ }^{10}$ and were blinded to clinical information with consensus. The lumen and wall boundaries were manually traced. The lumen area, wall area, total vessel area and mean wall thickness on each axial image of all subjects were measured. Normalised wall index, defined as the wall area divided by the total vessel area, was calculated. The presence or absence of calcification, LRNC, IPH and luminal surface disruption, including ulcer or fibrous cap rupture, at each axial location was identified according to published criteria. ${ }^{11}$ For each plaque component, its area at each axial image was measured and its volume was calculated. Large LRNC was defined as LRNC which occupied $>40 \%$ of the wall area on any axial image. High-risk plaque (HRP) was defined as a lesion with large LRNC, IPH or luminal surface disruption. ${ }^{5}$ The luminal stenosis of carotid arteries was measured on three-dimensional (3D) TOF magnetic resonance angiography images reconstructed by maximum intensity projection algorithm using the North American Symptomatic Carotid Endarterectomy criteria, ${ }^{12}$ and the presence or absence of $\geq 50 \%$ stenosis was determined.

\section{Statistical analysis}

The nine imaging slices covering $18 \mathrm{~mm}$ centred at the bifurcation of the symptomatic carotid artery were included in the analysis. Continuous variables are presented as mean $\pm \mathrm{SD}$ or median, and categorical variables are expressed as number with percentage. MannWhitney $U$ test or $\chi^{2}$ test was used to compare plaque features between subjects in northern and southern China and between the CARE-II subjects included and excluded from this study. Multivariate linear and logistic regression models were performed to determine the differences in plaque measurements between subjects in northern and southern China. Age, sex and clinical risk factors that were significantly different $(\mathrm{p}<0.05)$ between the two groups in the univariate comparison were included as adjustments in the multivariate models. A value of $p<0.05$ was considered statistically significant without adjustment for multiple comparisons. All statistical analyses were performed using SPSS V.16.0.

\section{RESULTS}

The flow chart of recruitment of patients is presented in figure 1. In total, 279 subjects from the hospitals in northern and southern China were recruited into the study. Of the 279 subjects, 160 were excluded due to the following reasons: (1) side of symptomatic carotid artery was not available $(\mathrm{n}=86)$; (2) insufficient image quality $(\mathrm{n}=41)$; and (3) insufficient MRI coverage $(\mathrm{n}=33)$. Finally, 63 subjects in northern China (mean age: $59.1 \pm 8.6$ years old, 45 men) and 56 subjects in southern China (mean age: $60.4 \pm 8.6$ years old, 38 men) were included. Table 1 shows the clinical characteristics of this study population. Northern subjects had greater BMI $(24.7 \pm 3.1 \mathrm{~kg} /$ $\mathrm{m}^{2}$ vs $\left.23.0 \pm 2.9 \mathrm{~kg} / \mathrm{m}^{2}, \mathrm{p}=0.002\right)$, height $(169.3 \pm 5.7 \mathrm{~cm}$ vs $165.3 \pm 6.7 \mathrm{~cm}, \mathrm{p}=0.001)$ and weight $(71.0 \pm 10.4 \mathrm{~kg}$ vs $62.8 \pm 8.5 \mathrm{~kg}, \mathrm{p}<0.001)$ and were more likely to have a history of smoking $(55.6 \%$ vs $35.7 \%, \mathrm{p}=0.030)$ than southern subjects. In contrast, northern subjects had a lower prevalence of diabetes compared with those in southern China $(20.6 \%$ vs $39.3 \%$, $\mathrm{p}=0.026)$.

\section{Comparison of carotid plaque morphology}

The comparison of plaque morphology is shown in table 2 . 
1047 subjects from

\section{3 hospitals}
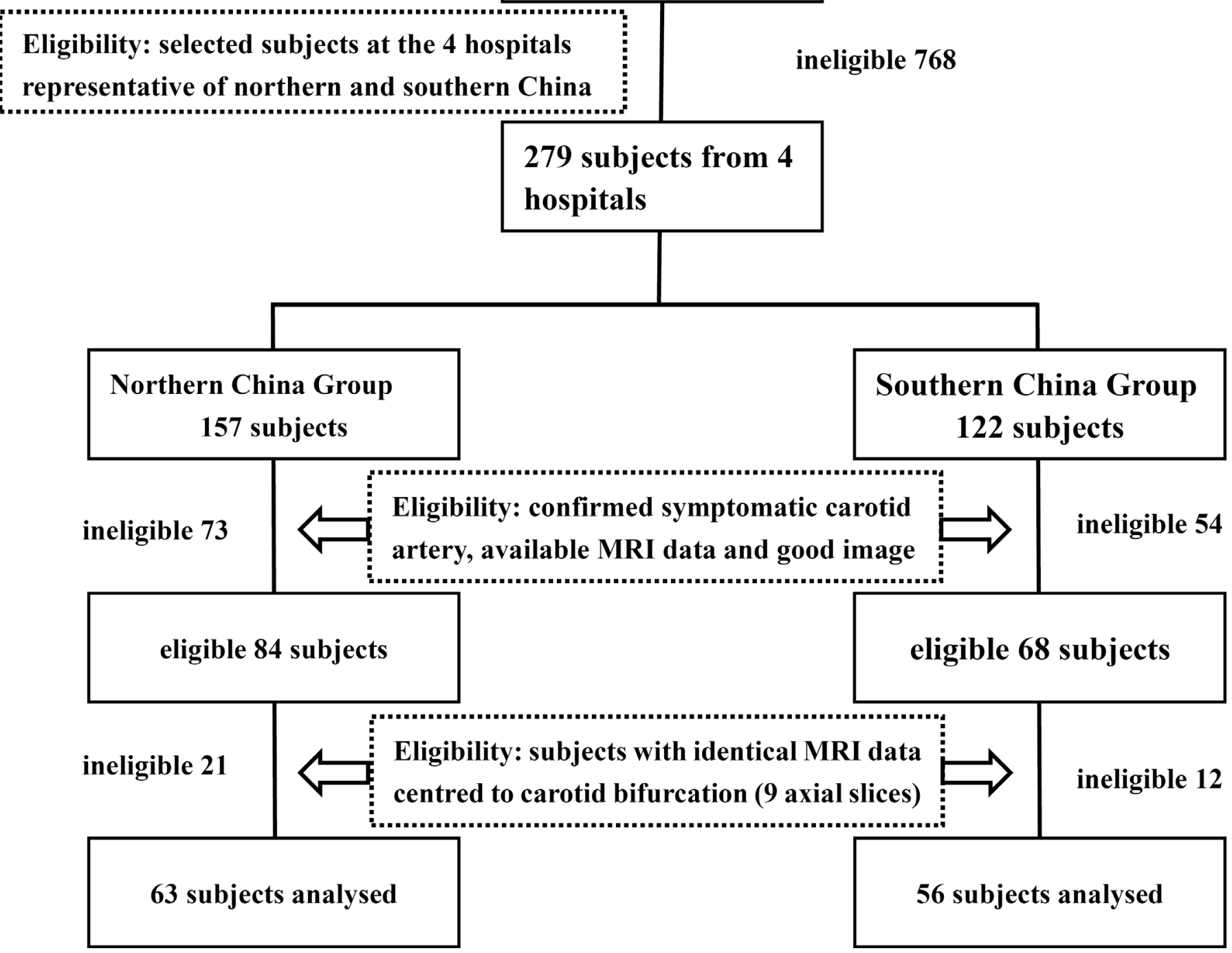

Figure 1 Flow chart of patient recruitment.

Before adjustment, northern subjects had significantly greater lumen area $\left(57.7 \pm 14.9 \mathrm{~mm}^{2}\right.$ vs $50.4 \pm 18.3 \mathrm{~mm}^{2}$, $\mathrm{p}=0.009)$, wall area $\left(38.4 \pm 13.1 \mathrm{~mm}^{2}\right.$ vs $31.9 \pm 11.7 \mathrm{~mm}^{2}$, $\mathrm{p}<0.001)$, total vessel area $\left(96.1 \pm 20.2 \mathrm{~mm}^{2}\right.$ vs $\left.82.4 \pm 22.7 \mathrm{~mm}^{2}, \quad \mathrm{p}=0.001\right)$ and mean wall thickness $(1.25 \pm 0.43 \mathrm{~mm}$ vs $1.13 \pm 0.40 \mathrm{~mm}, \mathrm{p}=0.019)$ than southern subjects (figure 2). However, mean normalised wall index and prevalence of $\geq 50 \%$ stenosis were not significantly different between the two groups. After adjusting for age, sex, BMI and history of smoking and diabetes, wall area $(\beta$ : $6.72,95 \%$ CI 2.28 to $11.17, \mathrm{p}=0.003$ ) and total vessel area ( $\beta$ : $12.94,95 \%$ CI 5.24 to $21.51, p=0.001$ ) remained significantly greater and lumen area was marginally greater ( $\beta$ : $6.21,95 \% \mathrm{CI}-0.03$ to $12.45, \mathrm{p}=0.051$ ) in northern subjects compared with southern subjects (table 3 ). The difference in mean wall thickness was marginally not significant after adjustment $(p=0.076)$ and normalised wall index remained similar $(\mathrm{p}=0.499)$ between northern and southern subjects in multivariate analyses. The absolute vessel measurements, including lumen, wall and total vessel areas, were highly correlated with height, and the differences in the absolute vessel measurements between northern and southern subjects decreased after adjusting for height. The differences in lumen $(p=0.15)$ and wall area $(p=0.11)$ were no longer significant after adjusting for height (data not shown).

Comparison of carotid plaque components

The prevalence of IPH $(14.3 \%$ vs $5.4 \%, \mathrm{p}=0.106)$ and HRP (20.6\% vs $10.7 \%, \mathrm{p}=0.140)$ tended to be higher in the northern subjects than that in the southern subjects, although these differences were not statistically significant (table 2). Figure 3 shows a patient in northern China who had carotid plaque with IPH identified on T1W, T2W, TOF and MPRAGE images. The comparison of the prevalence of plaque components showed 
Table 1 Clinical characteristics of the study population

\begin{tabular}{|c|c|c|c|}
\hline & \multicolumn{2}{|c|}{ Mean \pm SD, or $\mathrm{n}(\%)$} & \multirow[b]{2}{*}{ P value* } \\
\hline & $\begin{array}{l}\text { Northern } \\
\text { subjects } \\
(\mathrm{n}=63)\end{array}$ & $\begin{array}{l}\text { Southern } \\
\text { subjects } \\
(n=56)\end{array}$ & \\
\hline Age, years & $59.1 \pm 8.6$ & $60.4 \pm 8.6$ & 0.449 \\
\hline Male, sex & $45(71.4)$ & $38(67.9)$ & 0.672 \\
\hline Body mass index, $\mathrm{kg} / \mathrm{m}^{2}$ & $24.7 \pm 3.1$ & $23.0 \pm 2.9$ & 0.002 \\
\hline Height, cm & $169.3 \pm 5.7$ & $165.3 \pm 6.7$ & 0.001 \\
\hline Weight, kg & $71.0 \pm 10.4$ & $62.8 \pm 8.5$ & $<0.001$ \\
\hline History of smoking & $35(55.6)$ & $20(35.7)$ & 0.030 \\
\hline History of hypertension & $40(63.5)$ & $41(73.2)$ & 0.256 \\
\hline $\begin{array}{l}\text { Systolic blood pressure, } \\
\mathrm{mm} \mathrm{Hg}\end{array}$ & $149.6 \pm 25.6$ & $148.0 \pm 22.2$ & 0.994 \\
\hline $\begin{array}{l}\text { Diastolic blood pressure, } \\
\mathrm{mm} \mathrm{Hg}\end{array}$ & $89.4 \pm 14.0$ & $87.4 \pm 12.1$ & 0.453 \\
\hline History of hyperlipidaemia & $30(47.6)$ & $28(50.0)$ & 0.795 \\
\hline LDL-C, mmol/L & $3.18 \pm 0.90$ & $3.17 \pm 1.09$ & $>0.99$ \\
\hline HDL-C, mmol/L & $1.24 \pm 0.97$ & $1.20 \pm 0.29$ & 0.300 \\
\hline $\mathrm{TC}, \mathrm{mmol} / \mathrm{L}$ & $4.69 \pm 1.19$ & $4.84 \pm 1.28$ & 0.598 \\
\hline $\mathrm{TG}, \mathrm{mmol} / \mathrm{L}$ & $1.70 \pm 1.08$ & $1.58 \pm 0.91$ & 0.747 \\
\hline $\begin{array}{l}\text { History of diabetes } \\
\text { mellitus }\end{array}$ & $13(20.6)$ & $22(39.3)$ & 0.026 \\
\hline $\begin{array}{l}\text { History of coronary heart } \\
\text { disease }\end{array}$ & $9(14.3)$ & $3(5.4)$ & 0.106 \\
\hline Statin use & $19(30.2)$ & $24(42.9)$ & 0.150 \\
\hline $\begin{array}{l}\text { Antihypertension } \\
\text { medication use }\end{array}$ & $29(46.0)$ & $30(53.6)$ & 0.412 \\
\hline
\end{tabular}

${ }^{*} \mathrm{P}$ values were calculated by Mann-Whitney $U$ test or $\chi^{2}$ test. HDL-C, high-density lipoprotein cholesterol; LDL-C, low-density lipoprotein cholesterol; TC, total cholesterol; TG, triglyceride.

no statistical differences in calcification $(38.1 \%$ vs $41.1 \%, \mathrm{p}=0.740)$, LRNC (60.3\% vs $55.4 \%, \mathrm{p}=0.584)$ and luminal surface disruption ( $11.1 \%$ vs $7.1 \%, \mathrm{p}=0.456)$ between northern and southern subjects before multivariate adjustment. For subjects with carotid calcified plaque, northern subjects had marginally significant larger volume of calcification $\left(19.9 \mathrm{~mm}^{3}\right.$ vs $8.0 \mathrm{~mm}^{3}$, $\mathrm{p}=0.050)$ than southern subjects. There was no significant difference in the volume of LRNC $\left(29.4 \mathrm{~mm}^{3}\right.$ vs $36.2 \mathrm{~mm}^{3}, \mathrm{p}=0.629$ ) between the northern and southern subjects. Multivariate regression analyses were further performed to compare the prevalence of calcification and LRNC and no significant differences were found in the prevalence of calcification (OR: $1.15,95 \% \mathrm{CI} 0.48$ to $2.79, p=0.754)$ and LRNC (OR: $1.54,95 \%$ CI 0.64 to 3.70 , $\mathrm{p}=0.331)$ between the northern and southern subjects after adjusting for age, sex, BMI, history of smoking and diabetes. When further adjusting for mean normlised wall index, the differences in the prevalence of calcification (OR: $1.02,95 \%$ CI 0.35 to $2.92, \mathrm{p}=0.977$ ) and LRNC (OR: $1.10,95 \% \mathrm{CI} 0.37$ to $3.30, \mathrm{p}=0.861$ ) were also not statistically significant. Multivariate analyses of
Table 2 Carotid plaque morphological and compositional characteristics

\begin{tabular}{|c|c|c|c|}
\hline & \multicolumn{2}{|c|}{$\begin{array}{l}\text { Mean } \pm \text { SD, } n(\%) \text { or } \\
\text { median }\end{array}$} & \multirow[b]{2}{*}{ P value* } \\
\hline & $\begin{array}{l}\text { Northern } \\
\text { subjects } \\
(n=63)\end{array}$ & $\begin{array}{l}\text { Southern } \\
\text { subjects } \\
(n=56)\end{array}$ & \\
\hline \multicolumn{4}{|l|}{ Carotid morphology } \\
\hline $\begin{array}{l}\text { Mean lumen area, } \\
\mathrm{mm}^{2}\end{array}$ & $57.7 \pm 14.9$ & $50.4 \pm 18.3$ & 0.009 \\
\hline Mean wall area, $\mathrm{mm}^{2}$ & $38.4 \pm 13.1$ & $31.9 \pm 11.7$ & $<0.001$ \\
\hline $\begin{array}{l}\text { Mean total vessel } \\
\text { area, } \mathrm{mm}^{2}\end{array}$ & $96.1 \pm 20.2$ & $82.4 \pm 22.7$ & 0.001 \\
\hline $\begin{array}{l}\text { Mean wall thickness, } \\
\mathrm{mm}\end{array}$ & $1.25 \pm 0.43$ & $1.13 \pm 0.40$ & 0.019 \\
\hline $\begin{array}{l}\text { Mean normalised wall } \\
\text { index, } \%\end{array}$ & $40.7 \pm 9.5$ & $40.2 \pm 10.4$ & 0.489 \\
\hline $\begin{array}{l}\text { Luminal stenosis } \\
\geq 50 \%\end{array}$ & $5(7.9)$ & $5(8.9)$ & $>0.99$ \\
\hline \multicolumn{4}{|l|}{$\begin{array}{l}\text { Presence of plaque } \\
\text { components }\end{array}$} \\
\hline Calcification & $24(38.1)$ & $23(41.1)$ & 0.740 \\
\hline $\begin{array}{l}\text { Lipid-rich necrotic } \\
\text { core }\end{array}$ & $38(60.3)$ & $31(55.4)$ & 0.584 \\
\hline $\begin{array}{l}\text { Intraplaque } \\
\text { haemorrhage }\end{array}$ & $9(14.3)$ & $3(5.4)$ & 0.106 \\
\hline $\begin{array}{l}\text { Luminal surface } \\
\text { disruption }\end{array}$ & $7(11.1)$ & $4(7.1)$ & 0.456 \\
\hline High-risk plaque & $13(20.6)$ & $6(10.7)$ & 0.140 \\
\hline \multicolumn{4}{|c|}{ Volume of plaque components $\dagger$} \\
\hline Calcification, $\mathrm{mm}^{3}$ & 19.9 & 8.0 & 0.050 \\
\hline $\begin{array}{l}\text { Lipid-rich necrotic } \\
\text { core, } \mathrm{mm}^{3}\end{array}$ & 29.4 & 36.2 & 0.629 \\
\hline
\end{tabular}

${ }^{*} \mathrm{P}$ values are Mann-Whitney $\mathrm{U}$ test or $\chi^{2}$ test between northern and southern subjects.

†Only subjects with the corresponding component present were included in the comparison.

other plaque characteristics and component volumes could not be reliably performed due to small sample size.

Comparison of carotid atherosclerosis between included and excluded subjects

In the present study, 119 subjects from the CARE-II study were included for final analysis. Of the 928 subjects who were excluded, 465 were selected for further comparison with the 119 subjects included. The other 463 subjects were not included in this comparison due to the following reasons: (1) side of symptomatic carotid artery was not available $(\mathrm{n}=442)$ and (2) insufficient MRI quality $(n=21)$. We found that the 119 subjects included had significantly greater areas for lumen $\left(54.3 \pm 16.9 \mathrm{~mm}^{2}\right.$ vs $\left.44.4 \pm 15.6 \mathrm{~mm}^{2}, \quad \mathrm{p}<0.001\right)$, wall $\left(35.4 \pm 12.8 \mathrm{~mm}^{2}\right.$ vs $\left.32.3 \pm 11.6 \mathrm{~mm}^{2}, \mathrm{p}=0.011\right)$ and total vessel $\left(89.6 \pm 22.4 \mathrm{~mm}^{2}\right.$ vs $\left.76.7 \pm 21.2 \mathrm{~mm}^{2}, \mathrm{p}<0.001\right)$ and smaller mean normalised wall index $(40.4 \% \pm 9.9 \%$ vs $42.2 \pm 9.9 \%, p=0.049)$ than the 

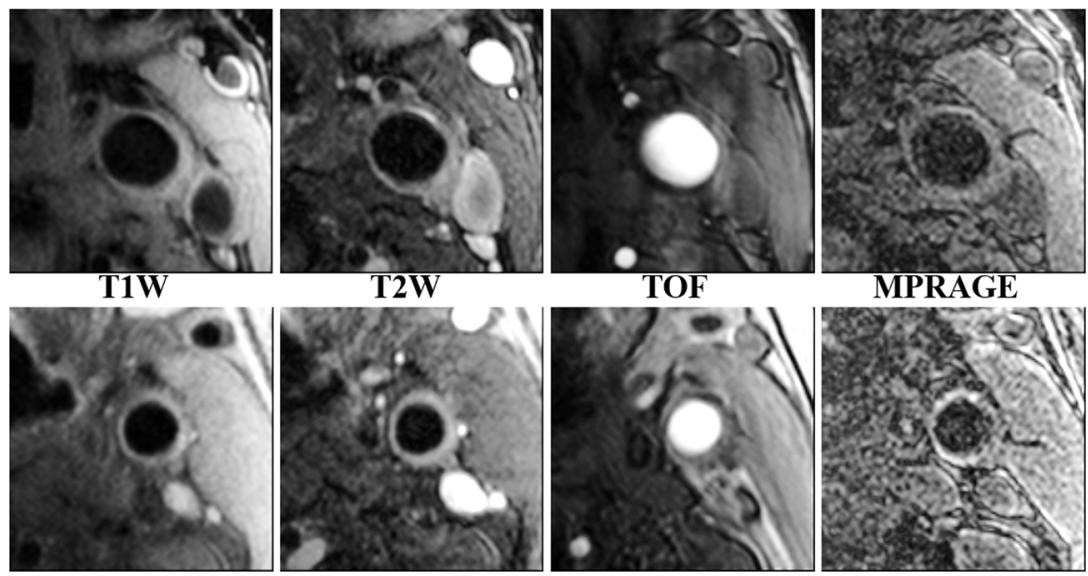

Figure 2 Comparison of carotid vessel morphology between subjects in northern and southern China. The top row represents a patient from the northern China group, and the bottom row represents a patient from the southern China group, with the same age and gender as the patient in the northern China group. All MRI images were taken from $8 \mathrm{~mm}$ below the carotid bifurcation. MPRAGE, magnetisation-prepared rapid acquisition gradient echo; T1W, T1-weighted; T2W, T2-weighted; TOF, time-of-flight.

465 subjects excluded. There were no significant differences in mean wall thickness and carotid compositional characteristics between the two groups (all $\mathrm{p}>0.05$ ). The results of the comparison are shown in the online supplementary table 1 .

\section{DISCUSSION}

This study investigated the differences in the characteristics of carotid atherosclerotic plaques in symptomatic subjects in northern and southern China using multicontrast vessel wall MRI. All data were enrolled from CARE-II, a multicentre, cross-sectional, observational study. We found that subjects in northern China had greater BMI, height and weight and were more likely to have a history of smoking than those in southern China, although the northern subjects were less likely to have diabetes than the southern subjects. For the carotid plaque characteristics, subjects in northern China were found to have larger lumen area, wall area, total vessel area, mean wall thickness and calcification volume compared with those in southern China, although with similar NWI. The prevalence of IPH and HRP tended to be higher in the northern subjects than in the southern subjects, although these differences were not statistically significant.

In the present study, subjects in northern China were found to have greater BMI, height and weight than those in southern China. These results are in line with the findings of previous studies carried out among different populations. ${ }^{13} 14$ In addition, we found that among the subjects studied, there were more smokers in northern China than in southern China. Our results were consistent with the study by Astell-Burt et $a l^{15}$ in which current tobacco smoking prevalence was found

Table 3 Multivariate regression models for comparing carotid plaque features

\begin{tabular}{|c|c|c|c|c|c|c|}
\hline & \multicolumn{3}{|c|}{ Multivariate model 1} & \multicolumn{3}{|c|}{ Multivariate model 2} \\
\hline & $\beta$ or $\mathrm{OR}^{\star}$ & $95 \% \mathrm{Cl}$ & $P$ value & $\beta$ or OR* & $95 \% \mathrm{Cl}$ & $P$ value \\
\hline \multicolumn{7}{|l|}{ Carotid morphology } \\
\hline Mean wall area, $\mathrm{mm}^{2}$ & 6.72 & 2.28 to 11.17 & 0.003 & - & - & - \\
\hline Mean total vessel area, $\mathrm{mm}^{2}$ & 12.94 & 5.24 to 21.51 & 0.001 & - & - & - \\
\hline Mean normalised wall index, \% & 1.28 & -2.46 to 5.01 & 0.499 & - & - & - \\
\hline \multicolumn{7}{|l|}{ Presence of plaque components } \\
\hline Calcification & 1.15 & 0.48 to 2.79 & 0.754 & 1.02 & 0.35 to 2.92 & 0.977 \\
\hline Lipid-rich necrotic core & 1.54 & 0.64 to 3.70 & 0.331 & 1.10 & 0.37 to 3.30 & 0.861 \\
\hline
\end{tabular}

Model 1 adjusting for age, sex, body mass index, history of smoking and diabetes. Model 2 further adjusting for the factors in model 1 and mean normalised wall index.

*Values are the difference in plaque measurements between northern and southern subjects using the linear regression slope $(\beta)$ for continuous measurements (plaque morphology) or the logistic regression OR for binary measurements (presence of plaque components). 


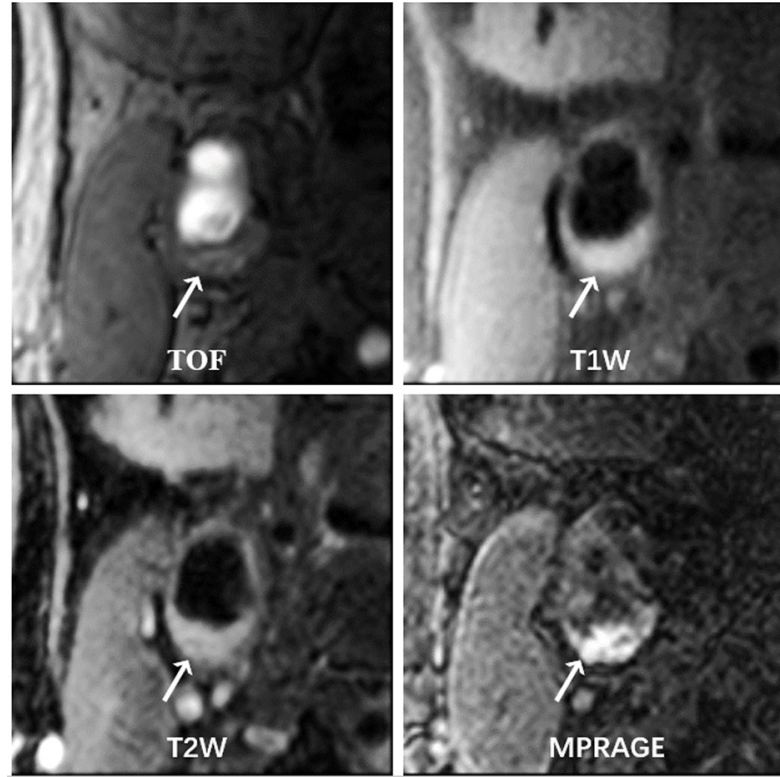

Figure 3 Example of a carotid atherosclerotic lesion with intraplaque haemorrhage (IPH) of a patient in the northern China group using multicontrast carotid vessel wall imaging. The IPH can be seen in the right carotid bifurcation, which is characterised by hyperintensities on TOF, T1W and MPRAGE images (arrow). MPRAGE, magnetisation-prepared rapid acquisition gradient echo; T1W, T1-weighted; T2W, T2weighted; TOF, time-of-flight.

to be higher in the northern provinces than in the southern provinces. The present study also demonstrated that subjects in southern China had higher prevalence of diabetes compared with those in northern China $(39.3 \%$ vs $20.6 \%, \mathrm{p}=0.026)$. This difference is contradictory to previous studies which suggested that diabetes in the general population is more common in the northern region of China than in the southern region. ${ }^{16}$ However, our study is of a symptomatic population, which has a different distribution of risk factors relative to the general population.

In this study, we compared the characteristics of carotid artery morphology between subjects in northern and southern China and found that subjects in northern China had significantly larger vessel size than those in southern China, even after adjusting for age, gender, BMI, smoking and diabetes. This finding implies that there might be geographical variation in carotid artery size between patients in northern and southern China. The geographical variation in carotid artery size could be explained by the differences in the genetic diversity or environmental factors (such as temperature). ${ }^{1718}$ In the present study, we also found that after adjusting for height, the differences in absolute vessel dimensions between subjects in northern and southern China decreased, suggesting that this phenomenon might be derived at least in part from the differences in body size rather than atherosclerotic disease in the arterial wall. Furthermore, total vessel area was correlated with height and weight in our study $(r=0.50$ and $r=0.39$, respectively, $\mathrm{p}<0.001)$, similar to a previous report by Polak et $a l^{17}$ that found that the outer diameter of the common carotid artery was positively correlated with height and weight $(\mathrm{r}=0.33$ and $\mathrm{r}=0.30$, respectively; $\mathrm{p}<0.0001)$. On the other hand, arterial dilatation may be present when the temperature is lower, ${ }^{18}$ or in response to moderate or advanced atherosclerosis. ${ }^{19}$ Vessel diameters were subject to complex regulation involving wall thickness, hypertension, low-density lipoprotein cholesterol levels and alcohol consumption. ${ }^{20}$ More studies need to be performed to investigate differences in this aspect.

The present study also suggested that subjects in northern China may be more likely to have IPH $(14.3 \%$ vs $5.4 \%, \mathrm{p}=0.106)$ and HRP (20.6\% vs $10.7 \%, \mathrm{p}=0.140$ ) compared with those in southern China, although these differences were not statistically significant. A larger cohort study needs to be performed to further investigate such differences. A study by van den Bouwhuijsen $e t a l^{21}$ noted that hypertension and current smoking were both associated with the presence of IPH (OR: 1.4, $95 \%$ CI 1.1 to 1.8 and OR: $1.6,95 \%$ CI 1.2 to 2.3 , respectively). Our study revealed that northern China had significantly more smokers than southern China, suggesting that the higher prevalence of smoking among subjects in northern China may contribute to this region's higher prevalence of IPH. A previous study demonstrated that endothelial nicotine receptors play an important stimulating role in angiogenesis, which is assumed to be a major cause of IPH. ${ }^{22}$

In addition, we found that subjects in northern China had marginally significantly larger volume of calcification compared with those in southern China. A study by van den Bouwhuijsen $e t a l^{23}$ revealed that the larger volume of calcification in carotid plaques was associated with a higher prevalence of IPH in asymptomatic patients. In the present study, we found that subjects in northern China tended to have a higher prevalence of IPH than those in southern China, suggesting that the larger volume of calcification in patients in northern China may be attributed to their higher prevalence of IPH. Nevertheless, the mechanism for the association between carotid plaque calcification volume and the prevalence of IPH remains unclear. This may be explained by the fact that IPH induces intraplaque inflammation by recruiting inflammatory contents, ${ }^{24}$ while chronic inflammation links to calcium deposits. ${ }^{25}$ Although the presence of calcification in carotid plaques has been traditionally considered a protective factor, ${ }^{26}$ more studies have highlighted that the presence of calcification with certain size $\mathrm{e}^{23}$ and location ${ }^{27}$ in carotid plaques may increase plaque vulnerability. The marginally significant differences in the volume of calcification $(p=0.050)$ and the presence of IPH $(p=0.106)$ between subjects in northern and southern China might be due to the insufficient sample size in this study.

Our study has several limitations. First, the sample size was small. Future studies with larger sample size to investigate geographical differences in the characteristics of 
carotid plaques are warranted. Second, only two provinces, Heilongjiang and Guangdong, were selected to be representative of northern and southern China, respectively. However, there could be inhomogeneity in the subjects from different provinces not only in northern but also in southern China. In future studies, it is necessary to include subjects from more provinces in each geographical region. Third, we enrolled subjects with existing carotid plaques, but few subjects $(8.4 \%)$ had advanced lesions with $\geq 50 \%$ carotid stenosis. Future studies are suggested to include subjects with a wide range of plaque severity. Fourth, carotid vessel wall imaging was performed with a two-dimensional multicontrast imaging technique, which yields limited longitudinal coverage $(32 \mathrm{~mm})$ and partial volume effect. Recently, 3D vessel wall MRI techniques with large coverage have been proposed for plaque assessment of carotid arteries. ${ }^{28}$ These 3D imaging techniques allow comprehensive evaluation of atherosclerotic disease, particularly for lesions that occurred in more proximal common carotid artery and more distal internal carotid artery segments. Fifth, due to the small sample size and hypothesis-generating nature of the study, we did not adjust $p$ values for multiple comparisons. Findings in this study need to be confirmed in larger studies. Finally, the genetic contributions to the variation of carotid plaques in different regions could not be investigated due to lack of blood sample in the study.

In conclusion, subjects in northern China have significantly larger vessel size and may have a higher prevalence of vulnerable plaques than those in southern China. Our findings provide additional perspective to optimise the management of cerebrovascular disease in individuals in different regions in China.

\section{Author affiliations}

${ }^{1}$ Center for Brain Disorders Research, Capital Medical University and Beijing Institute of Brain Disorders, Beijing, China

${ }^{2}$ Department of Radiology, Fourth Hospital of Harbin Medical University, Harbin, Heilongjiang, China

${ }^{3}$ Department of Surgery, University of Washington, Seattle, Washington, USA ${ }^{4}$ Department of Radiology, University of Washington, Seattle, Washington, USA ${ }^{5}$ Center for Biomedical Imaging Research, Department of Biomedical Engineering, Tsinghua University School of Medicine, Tsinghua University, Beijing, China

Contributors $\mathrm{XZ}$ and $\mathrm{CY}$ conceived the overall study and handled funding and supervision. XZ, YJ and DW acquired and interpreted the data. DY, YJ and XZ drafted the manuscript. DY, YJ, XZ, HW and DH performed the statistical analysis. CY provided technology support and made critical revision to the manuscript. All authors read and approved the content of this manuscript.

Funding This study was supported by grants from the National Natural Science Foundation of China (81771825), Beijing Municipal Science and Technology Commission (D171100003017003), and the Ministry of Science and Technology of the People's Republic of China (2017YFC1307904).

Competing interests None declared.

Patient consent for publication Not required.

Ethics approval The study protocol was approved by the institutional review board, and written consent form was obtained from each subject.

Provenance and peer review Not commissioned; externally peer reviewed. Data availability statement Data are available upon reasonable request.
Open access This is an open access article distributed in accordance with the Creative Commons Attribution Non Commercial (CC BY-NC 4.0) license, which permits others to distribute, remix, adapt, build upon this work non-commercially, and license their derivative works on different terms, provided the original work is properly cited, appropriate credit is given, any changes made indicated, and the use is non-commercial. See: http://creativecommons.org/licenses/by-nc/4.0/.

ORCID iD

Dandan Yang http://orcid.org/0000-0002-6528-0846

\section{REFERENCES}

1 Lozano R, Naghavi M, Foreman K, et al. Global and regional mortality from 235 causes of death for 20 age groups in 1990 and 2010: a systematic analysis for the global burden of disease study 2010. Lancet 2012;380:2095-128.

2 Murray CJL, Vos T, Lozano R, et al. Disability-adjusted life years (DALYs) for 291 diseases and injuries in 21 regions, 1990-2010: a systematic analysis for the global burden of disease study 2010. Lancet 2012;380:2197-223.

3 Liu L, Wang D, Wong KSL, et al. Stroke and stroke care in China: huge burden, significant workload, and a national priority. Stroke 2011;42:3651-4.

4 Wang W, Jiang B, Sun $\mathrm{H}$, et al. Prevalence, Incidence, and Mortality of Stroke in China: Results from a Nationwide Population-Based Survey of 480687 Adults. Circulation 2017;135:759-71.

5 Underhill HR, Hatsukami TS, Cai J, et al. A noninvasive imaging approach to assess plaque severity: the carotid atherosclerosis score. AJNR Am J Neuroradiol 2010;31:1068-75.

6 Pu Y, Liu L, Wang Y, et al. Geographic and sex difference in the distribution of intracranial atherosclerosis in China. Stroke 2013;44:2109-14.

7 Luo Y, Polissar N, Han C, et al. Accuracy and uniqueness of three in vivo measurements of atherosclerotic carotid plaque morphology with black blood MRI. Magn Reson Med 2003;50:75-82.

8 Saam T, Ferguson MS, Yarnykh VL, et al. Quantitative evaluation of carotid plaque composition by in vivo MRI. Arterioscler Thromb Vasc Biol 2005;25:234-9.

9 Zhao X, Li R, Hippe DS, et al. Chinese atherosclerosis risk evaluation (care II) study: a novel cross-sectional, multicentre study of the prevalence of high-risk atherosclerotic carotid plaque in Chinese patients with ischaemic cerebrovascular events-design and rationale. Stroke Vasc Neurol 2017;2:15-20.

10 Kerwin W, Xu D, Liu F, et al. Magnetic resonance imaging of carotid atherosclerosis: plaque analysis. Top Magn Reson Imaging 2007:18:371-8.

11 Xu W-H, Li M-L, Gao S, et al. Middle cerebral artery intraplaque hemorrhage: prevalence and clinical relevance. Ann Neurol 2012;71:195-8

12 North American symptomatic carotid endarterectomy trial Collaborators. beneficial effect of carotid endarterectomy in symptomatic patients with high-grade carotid stenosis. N Engl J Med 1991;325:445-53.

13 Zhao L, Stamler J, Yan LL, et al. Blood pressure differences between Northern and southern Chinese: role of dietary factors: the International study on macronutrients and blood pressure. Hypertension 2004;43:1332-7.

14 Floyd B. Clinal variation in Chinese height and weight: evidence from the descendants of emigrants to Taiwan. Homo 2008;59:47-66.

15 Astell-Burt T, Zhang M, Feng X, et al. Geographical Inequality in Tobacco Control in China: Multilevel Evidence From 98058 Participants. Nicotine Tob Res 2018;20:755-65.

16 Yang L, Shao J, Bian Y, et al. Prevalence of type 2 diabetes mellitus among inland residents in China (2000-2014): A meta-analysis. $J$ Diabetes Investig 2016;7:845-52.

17 Polak JF, Kronmal RA, Tell GS, et al. Compensatory increase in common carotid artery diameter. Relation to blood pressure and artery intima-media thickness in older adults. cardiovascular health study. Stroke 1996;27:2012-5.

18 van Mil ACCM, Hartman Y, van Oorschot F, et al. Correlation of carotid artery reactivity with cardiovascular risk factors and coronary artery vasodilator responses in asymptomatic, healthy volunteers. $J$ Hypertens 2017;35:1026-34.

19 Della-Morte D, Gardener H, Dong C, et al. Association between carotid artery function and structure in the Northern Manhattan study. Front Neurol 2018;9:246.

20 Kiechl S, Willeit J. The natural course of atherosclerosis. Part II: vascular remodeling. Bruneck Study Group. Arterioscler Thromb Vasc Biol 1999;19:1491-8. 
21 van den Bouwhuijsen QJA, Vernooij MW, Hofman A, et al. Determinants of magnetic resonance imaging detected carotid plaque components: the Rotterdam study. Eur Heart J 2012;33:221-9.

22 Cooke JP. Angiogenesis and the role of the endothelial nicotinic acetylcholine receptor. Life Sci 2007;80:2347-51.

23 van den Bouwhuijsen QJA, Bos D, Ikram MA, et al. Coexistence of calcification, intraplaque hemorrhage and lipid core within the asymptomatic atherosclerotic carotid plaque: the Rotterdam study. Cerebrovasc Dis 2015;39:319-24.

24 Teng Z, Sadat U, Brown AJ, et al. Plaque hemorrhage in carotid artery disease: pathogenesis, clinical and biomechanical considerations. J Biomech 2014;47:847-58.
25 Abedin M, Tintut Y, Demer LL. Vascular calcification: mechanisms and clinical ramifications. Arterioscler Thromb Vasc Biol 2004;24:1161-70.

26 Huang $\mathrm{H}$, Virmani $\mathrm{R}$, Younis $\mathrm{H}$, et al. The impact of calcification on the biomechanical stability of atherosclerotic plaques. Circulation 2001;103:1051-6.

27 Sadat U, Teng Z, He J, et al. How does juxtaluminal calcium affect critical mechanical conditions in carotid atherosclerotic plaque? an exploratory study. IEEE Trans Biomed Eng 2014;61:35-40.

28 Zhou Z, Li R, Zhao X, et al. Evaluation of 3D multi-contrast joint intraand extracranial vessel wall cardiovascular magnetic resonance. $J$ Cardiovasc Magn Reson 2015;17:41. 